\title{
Phosphoproteomic Analysis Identifies Signaling Pathways Regulated by Curcumin in Human Colon Cancer Cells
}

\author{
TATSUHIRO SATO ${ }^{1,2}$, YUTAKA HIGUCHI $^{1}$, YOSHIO SHIBAGAKI $^{1}$ and SEISUKE HATTORI ${ }^{1}$ \\ ${ }^{1}$ Department of Biochemistry, School of Pharmaceutical Sciences, Kitasato University, Tokyo, Japan; \\ ${ }^{2}$ Division of Molecular Oncology, Aichi Cancer Center Research Institute, Nagoya, Japan
}

\begin{abstract}
Background: Curcumin, a major polyphenol of the spice turmeric, acts as a potent chemopreventive and chemotherapeutic agent in several cancer types, including colon cancer. Although various proteins have been shown to be affected by curcumin, how curcumin exerts its anticancer activity is not fully understood. Materials and Methods: Phosphoproteomic analyses were performed using SW480 and SW620 human colon cancer cells to identify curcuminaffected signaling pathways. Results: Curcumin inhibited the growth of the two cell lines in a dose-dependent manner. Thirty-nine curcumin-regulated phosphoproteins were identified, five of which are involved in cancer signaling pathways. Detailed analyses revealed that the mTORC1 and p53 signaling pathways are main targets of curcumin. Conclusion: Our results provide insight into the molecular mechanisms of the anticancer activities of curcumin and future molecular targets for its clinical application.
\end{abstract}

Curcumin (diferuloylmethane) is a major naturally-occurring polyphenol in the spice turmeric, that is made from the rhizome of Curcuma longa. Curcuma longa has traditionally been used in Asian countries as a medicinal herb for a wide range of diseases (1-3). Curcumin has been shown to possess a broad range of biological properties, including anti-oxidant, anti-inflammatory and anti-cancer activities (1-6). The anticancer activity of curcumin has been shown in cultured cells and animal studies, and various lines of evidence have revealed that curcumin inhibits not only tumourigenesis, but also tumour promotion and progression $(1,7-10)$. Curcumin has also shown beneficial results in some clinical trials, and

CThis article is freely accessible online.

orrespondence to: Tatsuhiro Sato, Division of Molecular Oncology, Aichi Cancer Center Research Institute, Aichi 464-8681, Japan. Email: satot@aichi-cc.jp

Key Words: Curcumin, Phosphoproteomic analysis, 2-D DIGE, AMPK/mTORC1, p53. very high doses were tolerable with no obvious side-effects (11-14). Studies using human cancer cell lines from various tissues have also reported that curcumin modulates diverse signaling pathways, such as those involving NF-kB, COX-2, cyclin D1, p53, Akt, mTOR, and mitogen-activated protein kinases (MAPKs) (1, 7-10).

Colon cancer is the third most common cancer in men and the second most common cancer in women worldwide. Epidemiological studies attribute the low incidence of colon cancer in India to curcumin-rich diets in the area (15). Many studies of how curcumin exerts its anti-cancer activity on colon cancer cells have been conducted. Curcumin inhibits human colon cancer cell growth by suppressing expression of the transcription factor EGR-1 (16), promoting cell-cycle arrest in the $G_{2} / M$ phase (7), reducing the expression of a cancer-associated micro RNA, miR-21 (17), and suppressing cyclin-dependent kinase 2 (CDK2) activity (18). Curcumin also shows anti-metastatic activity against colorectal cancer cells in vivo by up-regulating E-cadherin expression, and thus inhibiting epithelial-mesenchymal transition (EMT) (19). However, the whole picture of the anti-cancer action of curcumin still remains to be clarified.

In most intracellular signaling pathways, protein phosphorylation plays very important roles. Therefore, we examined the effect of curcumin on cell growth in two human colon cancer cell lines, SW480 and SW620 (20). We investigated global changes in the phosphoproteome induced by curcumin treatment to comprehensively understand the mechanisms underlying the anti-proliferative effect of curcumin on the cells. The SW480 cell line is derived from a human colon adenocarcinoma, and SW620 cells are derived from a lymph node metastasis of the same patient.

We previously established a proteomic approach consisting of phosphoprotein enrichment and two-dimensional fluorescence difference gel electrophoresis (2-D DIGE) to analyze dynamic changes in the phosphoproteome upon activation of a given kinase. We globally identified substrates that are phosphorylated in the p38 MAP kinase and ERK signaling pathways (21-23). We employed this approach to characterize the signaling molecules regulated by curcumin 
treatment in SW480 and SW620 cells. We identified 39 curcumin-induced phosphoproteins, 5 of which were involved in cancer signaling pathways. This approach provides a comprehensive understanding of the anti-cancer activity of curcumin and useful potential targets for the treatment of colon cancer.

\section{Materials and Methods}

Reagents. Curcumin was purchased from Sigma-Aldrich. U0126 and 5-fluorouracil (5-FU) were purchased from Cell Signaling Technology (Danvers, MA, USA) and Wako Pure Chemical Industries (Osaka, Japan), respectively. All antibodies were purchased from Cell Signaling Technology.

Cell culture. SW480 and SW620 cells were cultured in DMEM supplemented with $10 \%$ foetal bovine serum and 100 unit/mL penicillin/streptomycin at $37^{\circ} \mathrm{C}$ in $5 \% \mathrm{CO}_{2}$.

Cell growth assay. Cells $\left(5 \times 10^{3} /\right.$ well $)$ were seeded onto $96-w e l l$ microtiter plates and incubated in the presence or absence of the indicated concentrations of curcumin. For the combination treatment, cells were cultured in medium containing $20 \mu \mathrm{M}$ curcumin and either $100 \mu \mathrm{M}$ U0126 or $100 \mu \mathrm{M} 5$-FU. At each time point, cells were washed twice with serum-free culture medium and counted using Cell Count Reagent (Nacalai Tesuque, Kyoto, Japan) according to the manufacturer's instructions. Triplicate cultures were analyzed for each time point.

Western blotting. Cells were lysed with a lysis buffer (1\% TritonX100, $150 \mathrm{mM} \mathrm{NaCl}, 50 \mathrm{mM}$ Tris-HCl pH 7.5, $1 \mathrm{mM}$ EDTA, 1× EDTA-free Protease Inhibitor Cocktail [Nacalai Tesuque]). The supernatants after centrifugation at $15,000 \times g$ for 20 min at $4^{\circ} \mathrm{C}$ were mixed with $1 / 2$ volume of $3 \times$ SDS sample buffer ( $9 \%$ SDS, $15 \%$ glycerol, $187 \mathrm{mM}$ Tris- $\mathrm{HCl}$ (pH 6.8), 15\% 2-mercaptoethanol) and incubated at $95^{\circ} \mathrm{C}$ for $5 \mathrm{~min}$. The proteins were resolved by SDS-PAGE, transferred onto polyvinylidene difluoride membranes, and detected using specific antibodies.

Two-dimensional fluorescence difference gel electrophoresis. Cells $\left(1 \times 10^{7}\right)$ were treated with or without $200 \mu \mathrm{M}$ curcumin for $1 \mathrm{~h}$ and the lysates were enriched for phosphoproteins using a Phosphoprotein Purification kit (QIAGEN, Valencia, CA, USA). Interfering materials were removed using a 2-D Clean-Up kit (GE Healthcare, Chicago, IL, USA), then the phosphoprotein-enriched samples from curcumin-treated and control cells (40 $\mu \mathrm{g}$ each) were labelled with $0.5 \mu \mathrm{g}$ of IC3-OSu and IC5-OSu florescent dyes (DOJINDO Laboratories, Kamimashiki, Kumamoto, JAPAN), respectively, for $30 \mathrm{~min}$ on ice in a buffer containing $30 \mathrm{mM}$ Tris$\mathrm{HCl}(\mathrm{pH} 8.5), 7 \mathrm{M}$ urea, $2 \mathrm{M}$ thiourea and 4\% (w/v) 3-(3cholamidepropyl)dimethylammonio-1-propanesulphonate (CHAPS). The reaction was quenched with 10 nmole lysine, then the two labelled samples and unlabelled phosphoprotein-enriched samples from curcumin-treated and control cells ( $200 \mu \mathrm{g}$ each) were mixed, and subjected to first-dimension isoelectric focusing on immobilized $\mathrm{pH}$ gradient strips (24 cm; pH 3-10 nonlinear) using an Ettan IPGphor II system (GE Healthcare). Second-dimension separation was performed on $10 \%$ SDS-PAGE $(20 \times 24 \mathrm{~cm})$. Fluorescence images of the IC3-OSu and IC5-OSu dyes were obtained using a
Typhoon 9400 scanner (GE Healthcare) at $100 \mu \mathrm{m}$ resolution, and images were analysed by DeCyder software (version 5.01, GE Healthcare). For protein identification, the proteins were visualized using a SilverQuest silver staining kit (Invitrogen, Carlsbad, CA, USA) according to the manufacturer's instructions, and the spots of interest were excised and destained.

Protein identification by liquid chromatography-tandem mass spectrometry $(L C-M S / M S)$. Protein spots were subjected to in-gel tryptic digestion (24). The peptides produced were desalted and concentrated with a C18 Empore disc, eluted in $0.1 \%$ trifluoroacetic acid containing 50\% acetonitrile, and analyzed by nano-liquid chromatography-electrospray ionization mass spectrometry using a DiNa nano-LC system (KYA Technologies, Shinagawa, Tokyo, Japan) with an L-column 2 octyldecyl silane (0.05 mm by $100 \mathrm{~mm}, 3 \mu \mathrm{m}$; CERI, Bunkyo, Tokyo, Japan) coupled to a QStar Elite hybrid LC-MS/MS system (AB Sciex, Framingham, MA, USA). Proteins were identified using Protein Pilot version 3.0 software (AB Sciex) with default parameters. Proteins identified with more than $99 \%$ confidence (Protein Pilot Score $>2.0$ ) were adopted.

Bioinformatics analysis. The Gene Ontology (GO) database (http://www.geneontology.org/page/go-database) and the Kyoto Encyclopedia of Genes and Genomes (KEGG) database (http://www.genome.jp/kegg) were used with the DAVID Functional Annotation Tool (http://david.abcc.ncifcrf.gov) (25, 26) for functional annotation of the identified proteins.

\section{Results}

We first examined the anti-proliferative activity of curcumin in the SW480 and SW620 cells. The cells were cultured in the presence or absence of curcumin together with $10 \%$ foetal bovine serum to activate intracellular-growth signaling pathways. As shown in Figure 1A and B, curcumin inhibited the growth of both cell lines at concentrations of 10 to $200 \mu \mathrm{M}$ in a dose-dependent manner. The maximum effect was observed with 80 and $200 \mu \mathrm{M}$ curcumin. The extent of the inhibition after 2 days of incubation with curcumin was similar between the cell lines at each of the concentrations tested (Figure 1A and $\mathrm{B}$ ). The half maximal inhibitory concentration $\left(\mathrm{IC}_{50}\right)$ was around $20 \mu \mathrm{M}$ (Figure $1 \mathrm{C}$ ), which is similar to the value previously observed for colon cancer cell lines (7).

It is important to comprehensively investigate the effect of curcumin on the cell signaling pathways of cancer cells, which prompted us to apply a proteomic approach for this purpose. We previously developed a quantitative phosphoproteomic analytical method combining phosphoprotein enrichment by immobilized metal affinity chromatography, 2-D DIGE and protein identification by LC-MS/MS (21-23), which is schematically illustrated in Figure 2A.

Dynamic changes in the phosphoproteome of SW480 and SW620 cells induced by curcumin were visualized in cells cultured for $1 \mathrm{~h}$ with or without curcumin $(200 \mu \mathrm{M})$. The phosphoprotein-enriched samples from curcumin-treated and 
A

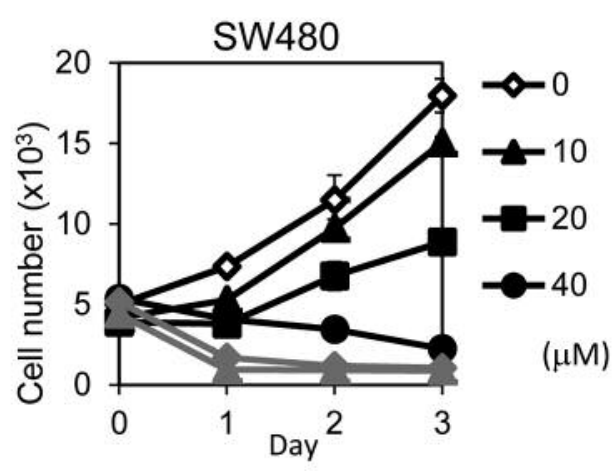

B

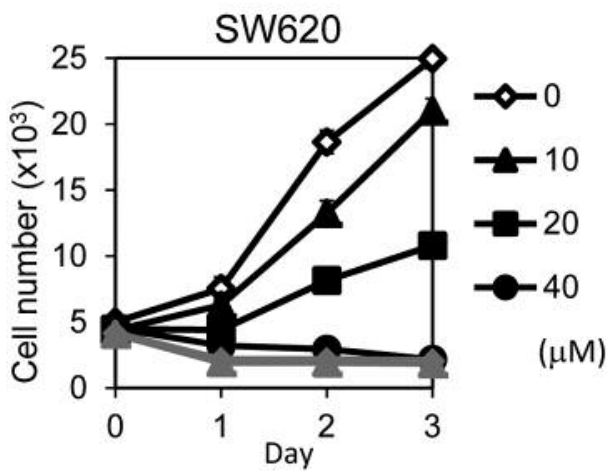

C

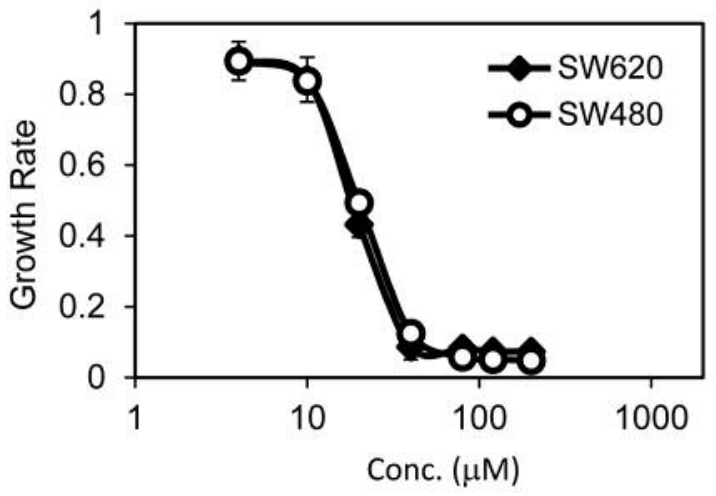

Figure 1. Effect of curcumin on colon cancer cell proliferation. (A, B) SW480 or SW620 cells were cultured with the indicated concentrations of curcumin and the cell number was recorded every $24 \mathrm{~h} .(C)$ After 3 days, the growth rate was determined and plotted against curcumin concentration. Error bars represent the standard error of the mean (SEM) from three independent experiments.

control cells were labelled with the fluorescent dyes IC5$\mathrm{OSu}$ (shown in red) and IC3-OSu (shown in green), respectively, and the two samples were mixed and analysed on the same 2-D gel. Unlabelled proteins from curcumintreated and control cells (200 $\mu \mathrm{g}$ each) were also mixed for protein identification.

As shown in Figure $2 \mathrm{~B}$ and $\mathrm{C}$, most protein spots are visible as yellow spots, resulting from the merging of red and green fluorescence, indicating their equal abundance. However, dozens of red and green spots, which are indicative of unequal abundance between the curcumintreated and control cells, were visible, suggesting dynamic changes in the phosphoproteome. The global changes in the phosphoproteome in SW480 cells were very similar to those induced in SW620 cells. Quantitative analysis of the fluorescence intensity of each spot by the DeCyder program identified 28 and 17 spots from SW480 cells (Figure 2D) and 48 and 28 protein spots from SW620 cells (Figure 2E) that exhibited more than a two-fold increase and decrease, respectively. Although the overall numbers of protein spots affected by the curcumin treatment differed slightly between two cell lines, a detailed comparison of each protein spot individually revealed that the changes in spot intensities in the two cell lines were very similar (Figure 2F). This suggests that curcumin suppresses the growth of colon cancer cells from primary and metastatic lesions by inhibiting common signaling pathways.

To identify the phosphoproteins regulated by curcumin, 57 spots (43 spots exhibiting more than a two-fold increase or decrease, and 14 spots exhibiting 1.3- to 1.5-fold increase or decrease) on 2-D DIGE of SW480 and SW620 cells were selected. The spots were excised after silver staining and subjected to tryptic digestion followed by LC-MS/MS analysis. From these spots, 39 unique proteins were identified (Table I). Gene ontology assignments for these proteins revealed enrichment in several categories including nucleic acid binding (14/39), mRNA processing factors (4/39) and translation factors (4/39) (Figure 3A). Classification according to biological processes indicated that most proteins were linked to protein metabolism and modification (17/39), pre-mRNA processing (5/39), and mRNA splicing (5/39) (Figure 3B). 


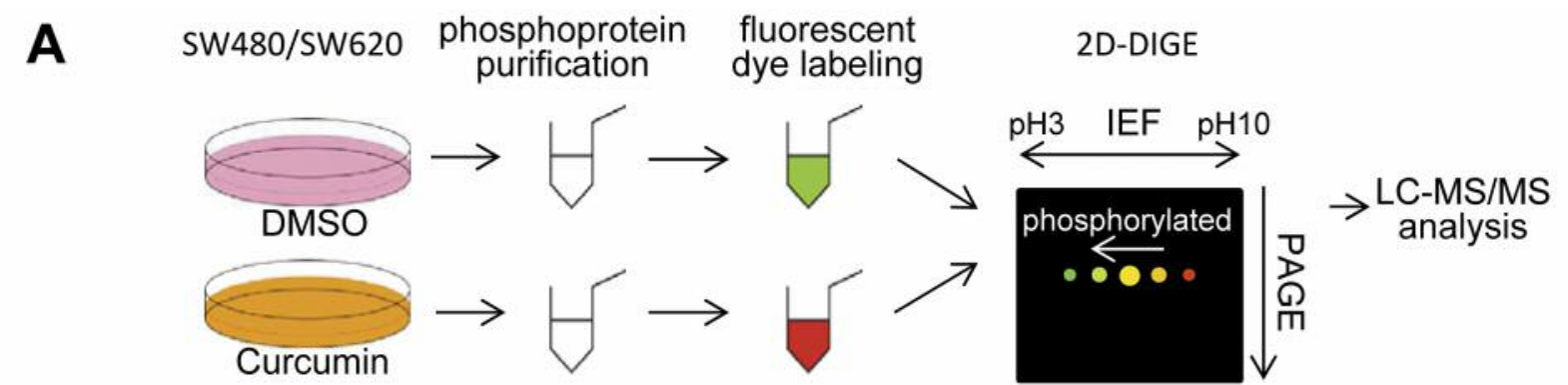

B

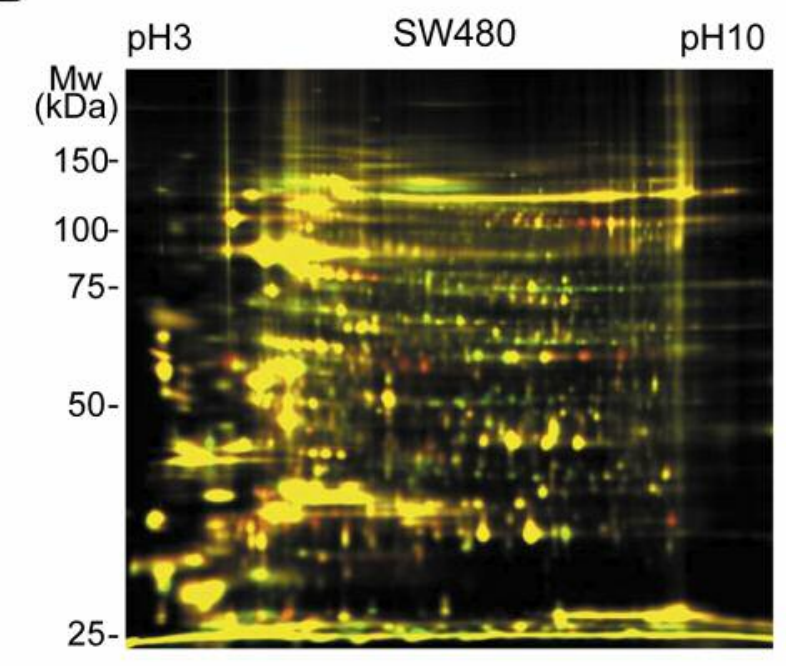

C

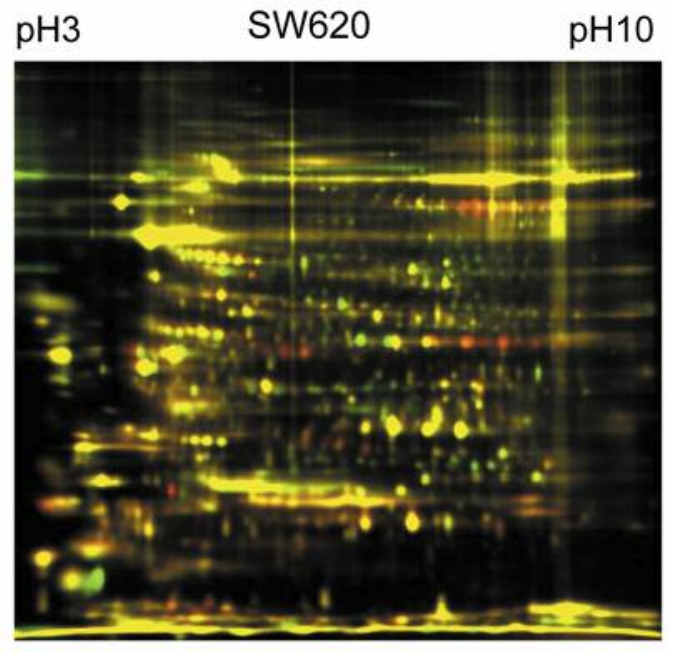

D
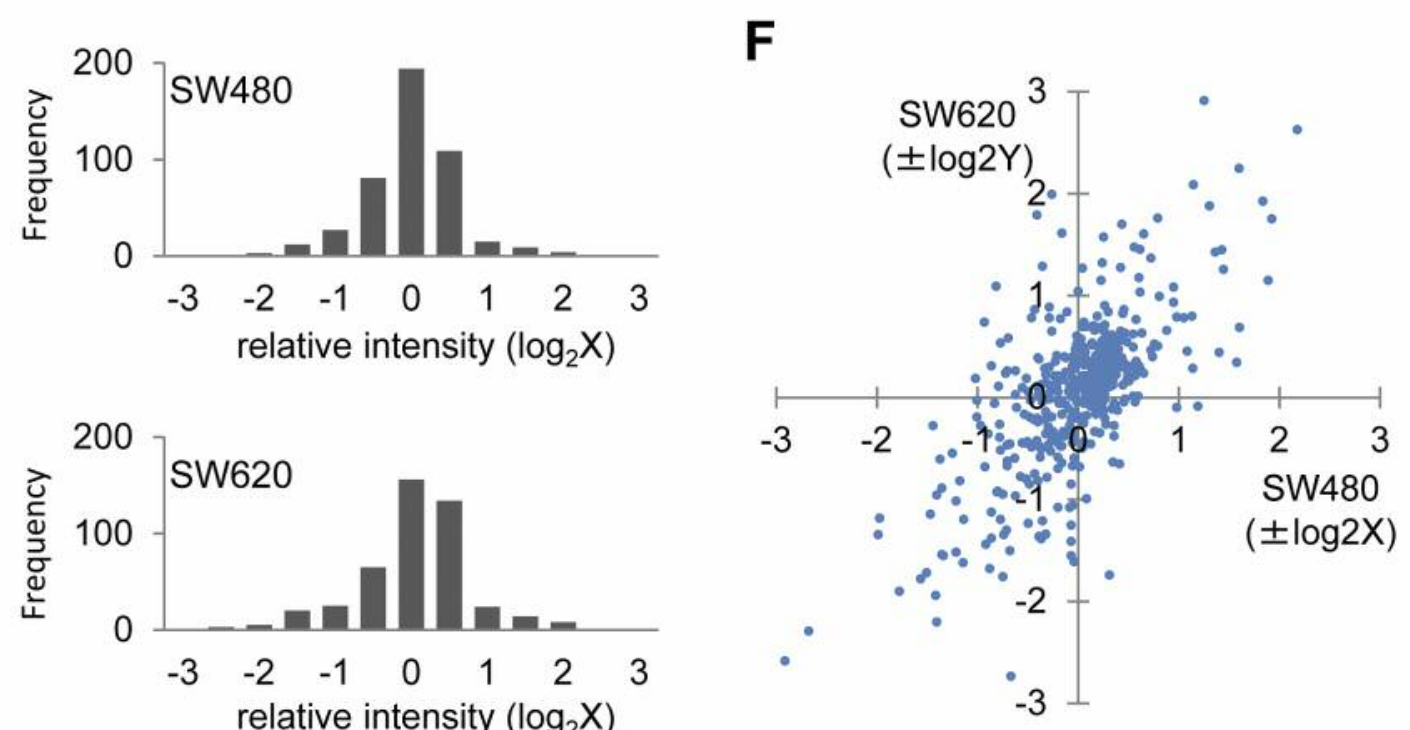

Figure 2. Two-dimensional fluorescence difference gel electrophoresis (2-D DIGE) analysis of phosphoproteomes from curcumin-treated and untreated colon cancer cells. (A) The quantitative phosphoproteomic approach employed in this study is schematically illustrated. Phosphoproteinenriched samples from cells treated with or without curcumin $(200 \mu \mathrm{M}, 1 \mathrm{~h})$ were purified and labelled with two fluorescent dyes, respectively. Labelled samples were mixed and analysed on the same 2-D gel. Protein spots with different intensities were excised and proteins in the spots were identified by tryptic digestion followed by liquid chromatography-tandem mass spectrometry (LC-MS/MS) analysis. (B, C) Representative 2-D DIGE result for phosphoproteomes from curcumin-treated $S W 480$ or SW620 cells (B and C, red) and control cells (green). (D, E) Distribution of the log2 spot volume ratios (curcumin/DMSO) of 2-D DIGE shown in Figure B (D) and $C(E)$. (F) Comparison of spot volume changes between the two cell lines. The two 2-D DIGE patterns were superimposed and the spot volume ratios of same spots were plotted. 


\section{A \\ Biological Process}

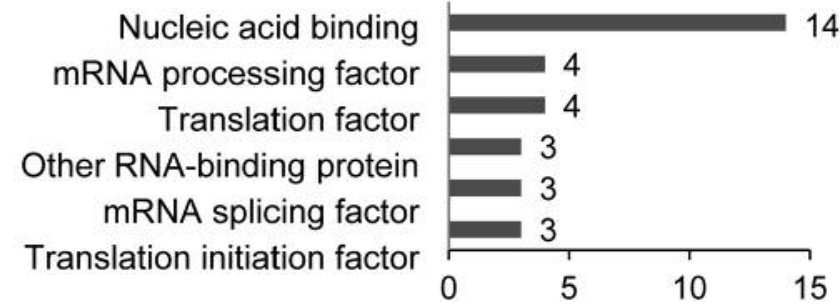

B

Molecular Function

Protein metabolism and modification

Pre-mRNA processing mRNA splicing

Regulation of lipid, FA and steroid metabolism

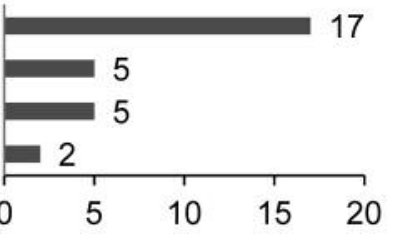

C
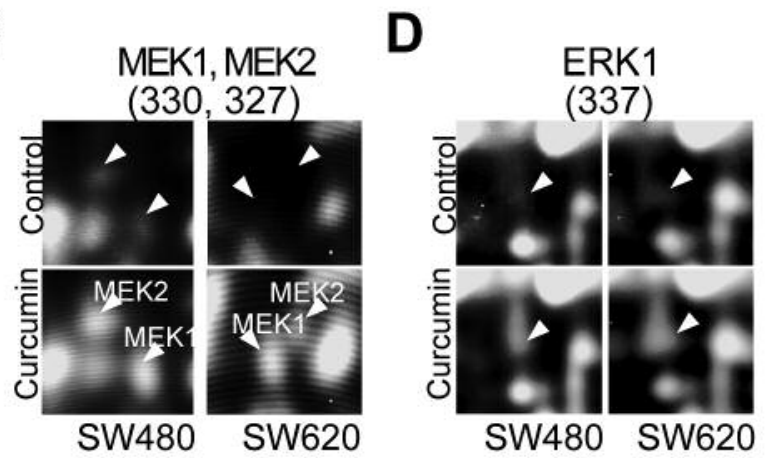

E

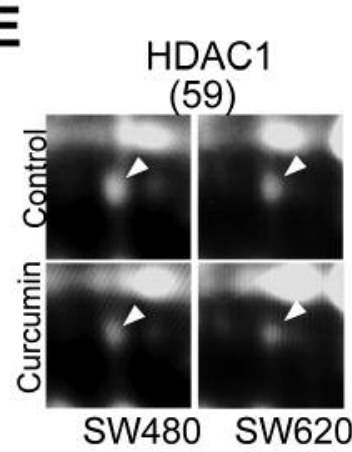

$\mathbf{F}$

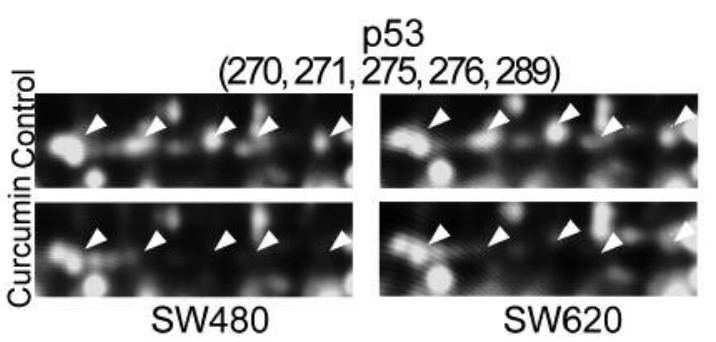

G

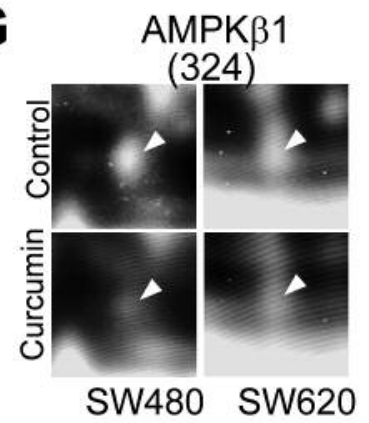

Figure 3. Identification and classification of proteins regulated by curcumin in SW480 and SW620 cells. (A, B) GO categorization by molecular function (A) and biological process $(B) .(C-G)$ Magnified images of protein spots (arrowheads) involved in cancer signalling.

Using the KEGG pathway database, the proteins in Table I were searched for involvement in cancer cell growth. Interestingly, five proteins, MEK1/2, ERK1, HDAC1 and p53, were found to be in the cancer pathway category. AMPK could also be classified in this category because of its function. Magnified views of the spots corresponding to
MEK1/2 (Figure 3C), ERK1 (Figure 3D), HDAC1 (Figure $3 \mathrm{E}$ ), p53 (Figure 3F), and the $\beta$ subunit of AMPK (AMPK $\beta 1$, Figure $3 \mathrm{G}$ ) are shown, demonstrating an increase (MEK1/2, ERK1) or decrease (HDAC1, p53, AMPK $\beta 1$ ) in spot intensity in response to curcumin treatment. This suggests that the phosphorylation of these molecules changed 
Table I. Phosphoproteins regulated by curcumin in SW480 and SW620 cells. Swiss-Prot accession number, spot volume ratio (fold difference), peptide coverage in protein identification, theoretical isoelectric point ( $\mathrm{pI})$, and theoretical molecular weight (Mw) are shown. Proteins identified with more than $99 \%$ confidence (Protein Pilot Score $>2.0$ ) were adopted.

\begin{tabular}{|c|c|c|c|c|c|c|c|c|}
\hline Spot No. & $\begin{array}{c}\text { Protein } \\
\text { name }\end{array}$ & $\begin{array}{l}\text { Gene } \\
\text { name }\end{array}$ & $\begin{array}{l}\text { Accession } \\
\text { No. }\end{array}$ & $\begin{array}{l}\text { Spot volume } \\
\text { ratio (control/ } \\
\text { curcumin) } \\
\text {-SW480- }\end{array}$ & $\begin{array}{l}\text { Spot volume } \\
\text { ratio (control/ } \\
\text { curcumin) } \\
\text {-SW620- }\end{array}$ & $\begin{array}{l}\text { Coverage } \\
(\%)\end{array}$ & $\mathrm{pI}$ & $\mathrm{Mw}$ \\
\hline $\begin{array}{l}270,271,275 \\
276,289\end{array}$ & Cellular tumor antigen p53 & P53 & P04637 & $\begin{array}{c}1.63,3.43 \\
6.4,2.96 \\
0.90\end{array}$ & $\begin{array}{c}1.38,3.73 \\
4.89,3.43 \\
0.75\end{array}$ & $\begin{array}{c}24.2,31.6, \\
31.0,16.0, \\
21.9\end{array}$ & 6.33 & 43,653 \\
\hline 272,278 & T-complex protein 1 subunit beta & $T C P B$ & P78371 & $7.54,1.23$ & $5.99,1.13$ & $25.0,53.5$ & 6.01 & 57,488 \\
\hline $335,336,340$ & Poly(rC)-binding protein 1 & $P C B P 1$ & Q15365 & $\begin{array}{l}3.97,1.43 \\
\quad 2.2\end{array}$ & $\begin{array}{l}2.54,0.88 \\
2.29\end{array}$ & $\begin{array}{l}43.3,19.7 \\
43.3\end{array}$ & 6.66 & 37,498 \\
\hline 335 & Poly(rC)-binding protein 2 & $P C B P 2$ & Q15366 & 3.97 & 2.54 & 42.2 & 6.33 & 38,580 \\
\hline $\begin{array}{r}149,152,155 \\
156,157,158\end{array}$ & Lamin-A/C & $L M N A$ & P02545 & $\begin{array}{l}1.96,2.65 \\
3.93,2.84, \\
2.32,2.38\end{array}$ & $\begin{array}{l}1.21,1.94 \\
2.27,3.29 \\
2.86,1.46\end{array}$ & $\begin{array}{c}45.5,45.2, \\
26.5,52.4, \\
43.2,47.9\end{array}$ & 6.57 & 74,139 \\
\hline 342 & RNA-binding protein 4 & $R B M 4$ & Q9BWF3 & 2.77 & 2.21 & 41.5 & 6.61 & 40,314 \\
\hline 129 & Zinc phosphodiesterase ELAC protein 2 & $R N Z 2$ & Q9BQ52 & 2.59 & 1.52 & 40.3 & 8.13 & 92,219 \\
\hline 179,180 & RNA-binding protein 39 & RBM39 & Q14498 & $2.21,2.32$ & $3.07,2.02$ & $16.6,25.3$ & 10.1 & 59,380 \\
\hline 79,80 & Gephyrin & $G E P H$ & Q9NQX3 & $2.53,1.84$ & $2.93,3.2$ & $22.3,27.2$ & 5.25 & 79,748 \\
\hline 57 & Peptidyl-prolyl cis-trans isomerase-like 4 & PPIL4 & Q8WUA2 & 1.91 & 1.42 & 18.5 & 5.63 & 57,225 \\
\hline 333,336 & Transcriptional activator protein Pur-alpha & PURA & Q00577 & $1.90,1.43$ & $1.60,-1.14$ & $40.7,38.5$ & 6.07 & 34,911 \\
\hline 199 & Bifunctional coenzyme A synthase & COASY & Q13057 & 1.82 & 2.6 & 9.8 & 6.51 & 62,329 \\
\hline $\begin{array}{r}206,207 \\
211,212\end{array}$ & Splicing factor U2AF $65 \mathrm{kDa}$ subunit & $U 2 A F 2$ & P26368 & $\begin{array}{c}1.71,1.89 \\
-2.47,-3.03\end{array}$ & $\begin{array}{c}2.29,2.71 \\
-3.68,-4.75\end{array}$ & $\begin{array}{l}44.0,46.7 \\
37.3,31.0\end{array}$ & 9.19 & 53,501 \\
\hline 66,72 & Eukaryotic translation initiation factor $4 \mathrm{~B}$ & $I F 4 B$ & P23588 & $1.71,-3.04$ & $1.43,-1.27$ & $51.1,27.3$ & 5.55 & 69,151 \\
\hline 206 & Dihydropyrimidinase-related protein 3 & $D P Y L 3$ & Q14195 & 1.71 & 2.29 & 35.4 & 6.04 & 61,963 \\
\hline 329 & Choline-phosphate cytidylyltransferase A & PCY1A & P49585 & 1.59 & 2.65 & 13.4 & 6.82 & 41,731 \\
\hline 329 & Choline-phosphate cytidylyltransferase B & $P C Y 1 B$ & Q9Y5K3 & 1.59 & 2.65 & 6 & 5.99 & 41,940 \\
\hline 324 & $\begin{array}{l}\text { 5'-AMP-activated protein } \\
\text { kinase subunit beta-1 }\end{array}$ & $A A K B 1$ & Q9Y478 & 1.75 & 1.9 & 18.5 & 5.94 & 30,382 \\
\hline 166 & $\begin{array}{l}\text { Fragile } \mathrm{X} \text { mental retardation } \\
\text { syndrome-related protein } 1\end{array}$ & FXR1 & P51114 & 1.21 & 1.48 & 22.1 & 5.84 & 69,721 \\
\hline 428 & Eukaryotic translation initiation factor $4 \mathrm{E}$ & $I F 4 E$ & P06730 & 1.53 & N/A & 24.4 & 5.79 & 25,097 \\
\hline 59 & Histone deacetylase 1 & HIDACl & Q13547 & 1.38 & 1.4 & 21 & 5.31 & 55,103 \\
\hline 19 & Reticulocalbin-1 & RCN1 & Q15293 & 1.32 & -1.31 & 19.6 & 4.86 & 38,890 \\
\hline 330 & $\begin{array}{l}\text { Dual specificity mitogen-activated } \\
\text { protein kinase kinase } 1\end{array}$ & $M P 2 K 1$ & Q02750 & 1.37 & 1.82 & 27.5 & 6.18 & 43,439 \\
\hline 425,427 & Cathepsin D & $C A T D$ & P07339 & $-2.19,-1.93$ & $-1.74,-1.91$ & $42.2,9.2$ & 6.1 & 44,552 \\
\hline 327,328 & $\begin{array}{l}\text { Dual specificity mitogen-activated } \\
\text { protein kinase kinase } 2\end{array}$ & $M P 2 K 2$ & P36507 & $-1.96,-1.40$ & $-3.39,-1.46$ & $17.2,36.8$ & 6.12 & 44,424 \\
\hline 371 & $\begin{array}{l}\text { Heterogeneous nuclear } \\
\text { ribonucleoproteins } \mathrm{C} 1 / \mathrm{C} 2\end{array}$ & $H N R P C$ & P07910 & 1.36 & 1.41 & 51.3 & 4.95 & 33,670 \\
\hline 371 & $\begin{array}{l}\text { Serine-threonine kinase } \\
\text { receptor-associated protein }\end{array}$ & STRAP & Q9Y3F4 & 1.36 & 1.41 & 38.6 & 4.98 & 38,438 \\
\hline 384 & Cathepsin Z & CATZ & Q9UBR2 & -2.28 & -1.26 & 26.4 & 6.7 & 33,868 \\
\hline 384 & Splicing factor, arginine/serine-rich 7 & SFRS7 & Q16629 & -2.28 & -1.26 & 31.5 & 11.83 & 27,367 \\
\hline 390 & Annexin A2 & ANXA2 & P07355 & 2.41 & N/A & 49.9 & 7.57 & 38,604 \\
\hline 219 & Protein disulfide-isomerase A3 & PDIA3 & P30101 & -2.57 & -2.69 & 34.1 & 5.98 & 56,782 \\
\hline 119 & Elongation factor 2 & $E F 2$ & P13639 & -4.52 & -6.18 & 38.3 & 6.41 & 95,338 \\
\hline 218 & $\begin{array}{l}\text { G patch domain and KOW } \\
\text { motifs-containing protein }\end{array}$ & GPCOW & Q92917 & -3.79 & -3.37 & 32.8 & 5.85 & 52,229 \\
\hline 47,48 & Kanadaptin & $N A D A P$ & Q9BWU0 & $1.32,1.47$ & $1.38,1.56$ & $36.2,34.9$ & 5.11 & 88,814 \\
\hline 46 & Ubiquitin carboxyl-terminal hydrolase 10 & $U B P 10$ & Q14694 & 1.15 & 1.33 & 6.8 & 5.19 & 87,134 \\
\hline d & Mitogen-activated protein kinase 1 & MK01 & P28482 & -1.35 & -3.25 & 45.6 & 6.5 & 41,390 \\
\hline $\mathrm{a}, \mathrm{b}$ & $\begin{array}{l}\text { Lamina-associated polypeptide } 2 \\
\text { isoform alpha }\end{array}$ & $L A P 2 A$ & P42166 & $1.55,2.56$ & $1.51,2.91$ & $22.5,29.1$ & 7.56 & 75,492 \\
\hline c & tRNA-dihydrouridine synthase 3-like & DUS3L & Q96G46 & 1.68 & 1.93 & 38.8 & 8.4 & 72,594 \\
\hline$e, f$ & $\begin{array}{l}\text { Eukaryotic translation initiation } \\
\text { factor } 2 \text { subunit } 1\end{array}$ & $I F 2 A$ & P20042 & N/A & $7.53,-1.07$ & $58.1,87.9$ & 5.02 & 36,112 \\
\hline
\end{tabular}



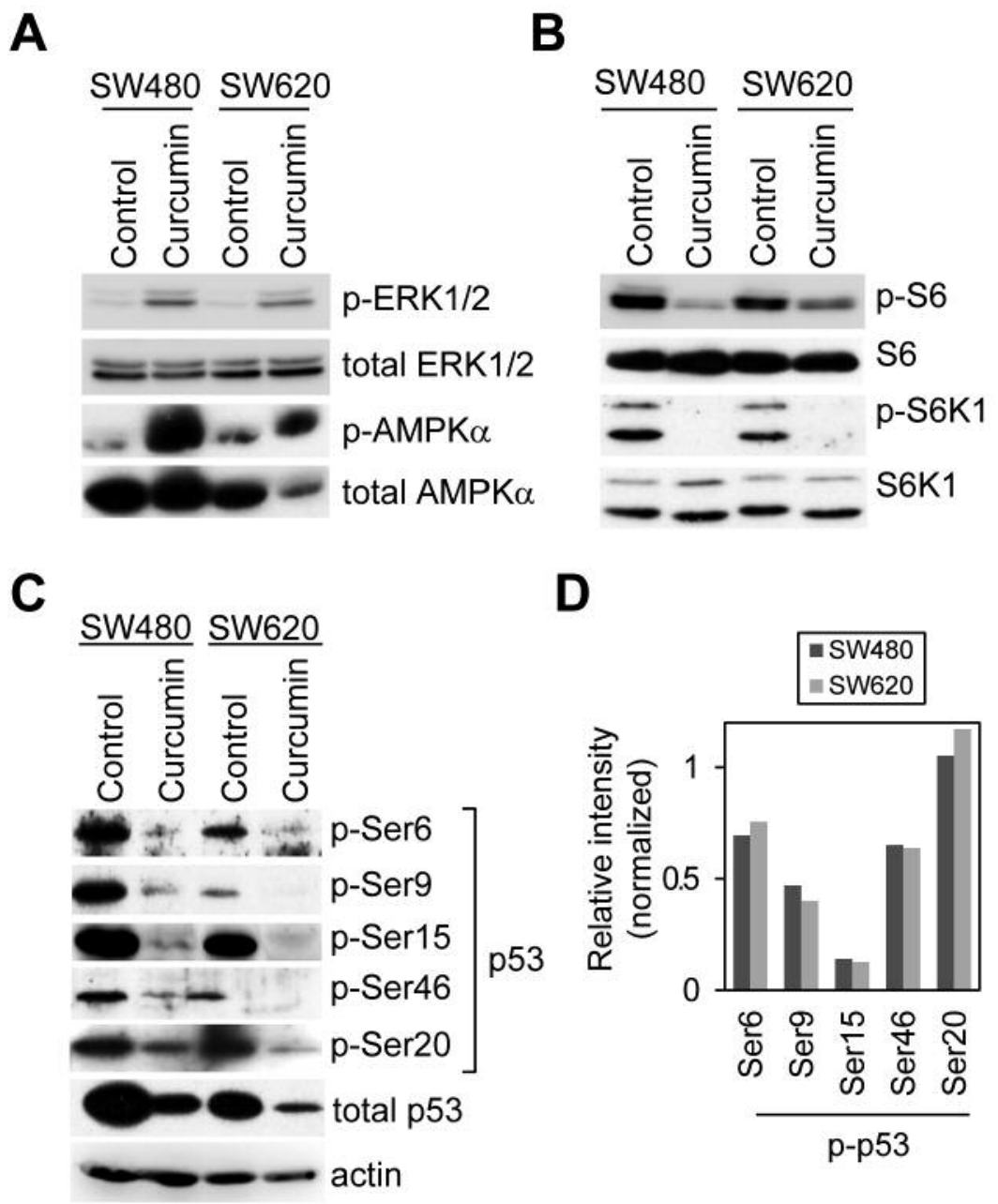

Figure 4. Regulation of phosphoproteins involved in cancer signaling by curcumin in SW480 and SW620 cells. (A-C) Cells treated with or without curcumin for $1 \mathrm{~h}$ were lysed and the proteins were analyzed by western blotting. (D) The graph shows the quantification of phospho-p53 shown in (C) after normalization to total protein.

substantially during the treatment. Interestingly, p53 was identified in five spots in a row (Figure 3F), consistent with its multiple phosphorylation sites (27).

We further investigated whether curcumin regulates ERK, p53 and AMPK activity under the same conditions by western blotting with the indicated phospho-specific antibodies. AMPK is a heterotrimeric protein comprising of $\alpha, \beta$ and $\gamma$ subunits that is thought to be activated when AMPK $\alpha$ is phosphorylated at threonine 172 (28). Curcumin induced phosphorylation of ERK and AMPK $\alpha$ Thr172 in these cells, indicating the activation of these kinases (Figure 4A). AMPK suppresses mTORC1 activity by phosphorylating TSC2, an upstream regulator of mTORC1 (29). To further validate the activation of AMPK, we therefore evaluated the activity of mTORC 1 by quantitating phosphorylation of p70 S6 kinase 1
(S6K1), a substrate of mTORC1 (Figure 4B). We also quantified the phosphorylation of S6, a direct substrate of S6K1. Both evaluations indicated that curcumin inhibited mTORC1 activity, consistent with AMPK activation.

We next extensively investigated p53 phosphorylation using a series of phosphospecific antibodies, because p53 can be phosphorylated at multiple sites by a variety of protein kinases (27). The same p53 site is phosphorylated by several different protein kinases; furthermore, distinct protein kinases phosphorylate several sites on p53. However, Ser6, Ser9 and Thr18 are phosphorylated only by casein kinase I (27). Surprisingly, curcumin treatment significantly decreased the p53 protein level despite equal sample loading, as confirmed by monitoring actin levels; and also decreased p53 phosphorylation at all of the residues examined (Figure 

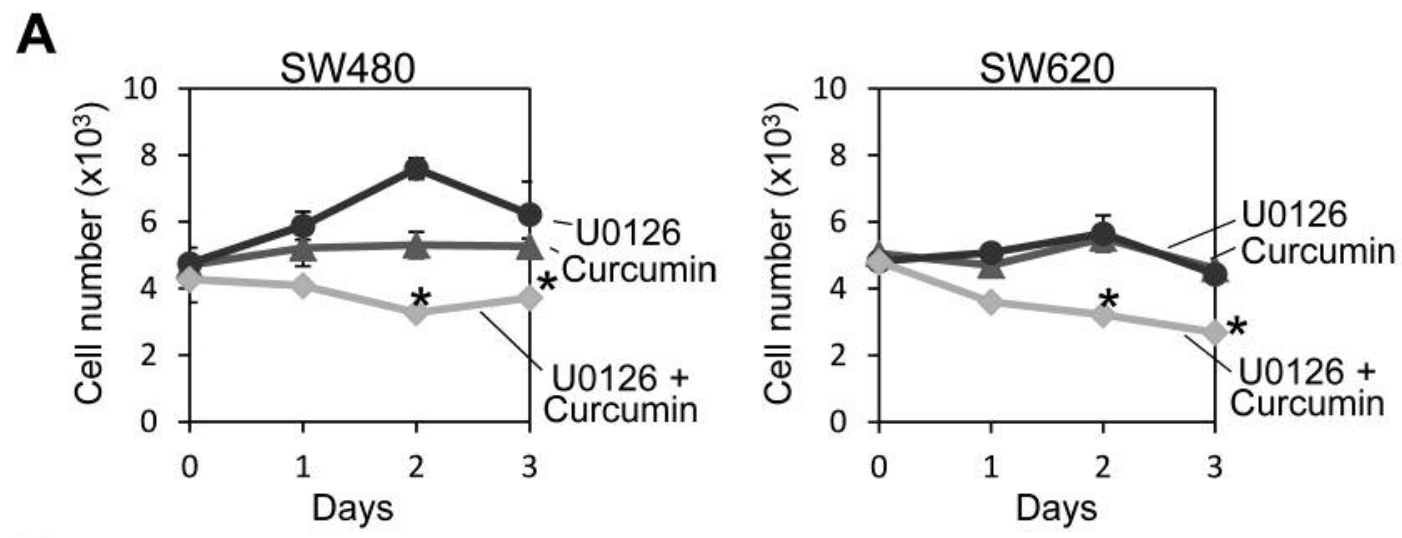

B
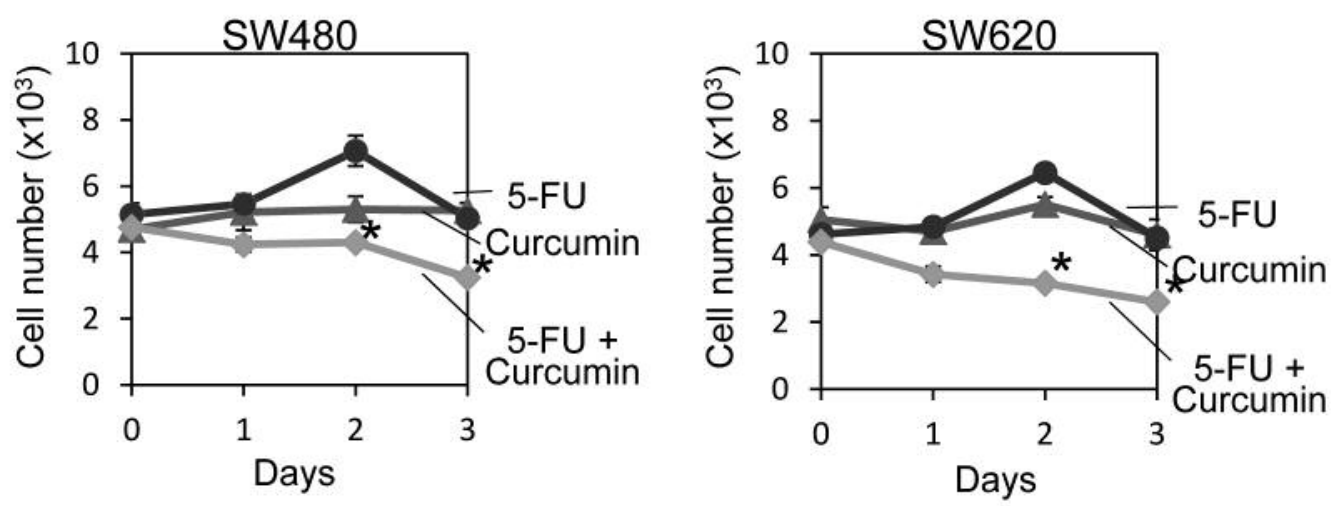

Figure 5. Synergistic anti-proliferative effect of curcumin and U0126 or 5-FU on SW480 and SW620 cells. (A, B) Numbers of SW480 or SW620 cells treated with curcumin, U0126, or 5-FU alone or in combination were counted every 24 h and plotted on graphs.

4C). The dramatic decrease in the p53 protein level suggests that the protein was degraded rapidly within the $1 \mathrm{~h}$ treatment. When normalized for expression level, phosphorylation of Ser15 was strongly reduced compared with that of other sites; Ser6, Ser9 and Ser46 phosphorylation were moderately suppressed, and phosphorylation at Ser20 was not affected (Figure 4D).

Given the finding that curcumin activated ERK and suppressed the mTORC1 pathway, we examined the combined effect of curcumin with a MEK inhibitor, U0126, on colon cancer cell viability (Figure 5). Whereas treatment with $20 \mu \mathrm{M}$ curcumin or $100 \mu \mathrm{M}$ U0126 alone did not significantly affect the number of SW480 cells, combined treatment with curcumin and U0126 significantly reduced the cell numbers (Figure 5A). Similar results were obtained in SW620 cells. This suggests that the anti-proliferative activity of curcumin is limited in part by the activation of the ERK pathway, and inactivating the ERK pathway by a MEK inhibitor significantly potentiated the effect of curcumin. Similar synergy was also observed with 5- FU, a potent inhibitor of DNA synthesis (Figure 5B).

\section{Discussion}

We investigated the changes induced by curcumin in the phosphoproteome of two colon cancer cell lines, and identified AMPK/mTORC1 and p53 as major targets of the treatment. Recently, curcumin-binding proteins in the HCT116 colon cancer cell line were globally identified using a cell-permeable curcumin probe tagged with biotin. The findings suggested that curcumin may exert its anticancer effects over multiple critical biological pathways including the EIF2, eIF4/p70S6K, mTOR signaling and mitochondrial dysfunction pathways (30). This is in accordance with our finding that the AMPK/mTOR pathway is critical for the inhibition of cell growth by curcumin.

mTORC1 has been shown to promote cell growth by phosphorylation of S6 and 4E-BP1, both of which stimulate protein synthesis. mTORC 1 inhibitors are used clinically to treat renal cancers (31). Therefore, mTORC1 may be one of the key targets via which curcumin inhibited cell growth in the two colon cancer cell lines in the present study. Pan et 
al. also described the activation of AMPK by curcumin in ovarian cancer cells (32).

Curcumin treatment dramatically reduced protein levels of p53. This finding might be somewhat strange because p53 is known to induce cell cycle arrest upon DNA damage. However, both alleles of TP53, the gene that encodes the tumor suppressor protein $\mathrm{p} 53$, have mutations giving rise to Arg273His and Cys309Pro substitutions in the two colon cancer cell lines studied here (20). Both are gain-of-function mutations that favour cancer cell growth, and inhibition of mutant p53 expression by RNA interference reduces cell proliferation, in vitro and in vivo tumourigenicity, and resistance to anticancer drugs (33). Degradation of the mutant p53 proteins in the colon cancer cell lines may, therefore, be another critical mechanism for the antiproliferative effect of curcumin.

This is the first investigation on dynamic changes in the phosphoproteome of colon cancer cells induced by curcumin. Our results may provide new insights into the molecular mechanism of anticancer activities of curcumin, and the signaling pathways identified in this study could be good targets for future treatment of cancer.

\section{Conflicts of Interest}

The Authors declare no conflict of interest.

\section{Acknowledgements}

This work was supported by JSPS KAKENHI Grant Number 15K19015, 23510261, and the Takeda Science Foundation.

\section{References}

1 Pavan AR, Silva GD, Jornada DH, Chiba DE, Fernandes GF, Man Chin C and Dos Santos JL: Unraveling the anticancer effect of curcumin and resveratrol. Nutrients 8: pii: E628, 2016.

2 Pulido-Moran M, Moreno-Fernandez J, Ramirez-Tortosa C and Ramirez-Tortosa M: Curcumin and Health. Molecules 21: 264, 2016.

3 Aggarwal BB and Sung B: Pharmacological basis for the role of curcumin in chronic diseases: an age-old spice with modern targets. Trends Pharmacol 30: 85-94, 2009.

4 Sordillo PP and Helson L: Curcumin suppression of cytokine release and cytokine storm. A potential therapy for patients with Ebola and other severe viral infections. In Vivo 29: 1-4, 2015.

5 Su CC, Yang JS, Lin SY, Lu HF, Lin SS, Chang YH, Huang WW, Li YC, Chang SJ and Chung JG: Curcumin inhibits WEHI-3 leukemia cells in BALB/c mice in vivo. In Vivo 22: 63-68, 2008.

6 Huang AC, Lin SY, Su CC, Lin SS, Ho CC, Hsia TC, Chiu TH, Yu CS, Ip SW, Lin TP and Chung JG: Effects of curcumin on N-bis(2-hydroxypropyl) nitrosamine (DHPN)-induced lung and liver tumorigenesis in BALB/c mice in vivo. In Vivo 22: 781785, 2008.

7 Van Erk MJ, Teuling E, Staal YC, Huybers S, Van Bladeren PJ, Aarts JM and Van Ommen B: Time- and dose-dependent effects of curcumin on gene expression in human colon cancer cells. J Carcinog 3: 8, 2004.

8 Temraz S, Mukherji D and Shamseddine A: Potential targets for colorectal cancer prevention. Int J Mol Sci 14: 17279-17303, 2013.

9 Li YH, Niu YB, Sun Y, Zhang F, Liu CX, Fan L and Mei QB: Role of phytochemicals in colorectal cancer prevention. World J Gastroenterol 21: 9262-9272, 2015.

10 Mirzaei H, Naseri G, Rezaee R, Mohammadi M, Banikazemi Z, Mirzaei HR, Salehi H, Peyvandi M, Pawelek JM and Sahebkar A: Curcumin: A new candidate for melanoma therapy? Int $\mathrm{J}$ Cancer 139: 1683-1695, 2016.

11 Rodriguez GA, Shah AH, Gersey ZC, Shah SS, Bregy A, Komotar RJ and Graham RM: Investigating the therapeutic role and molecular biology of curcumin as a treatment for glioblastoma. Ther Adv Med Oncol 8: 248-260, 2016.

12 Bimonte S, Barbieri A, Leongito M, Piccirillo M, Giudice A, Pivonello C, de Angelis C, Granata V, Palaia R and Izzo F: Curcumin anticancer studies in pancreatic cancer. Nutrients 8 , pii: E433, 2016.

13 Verma V: Relationship and interactions of curcumin with radiation therapy. World J Clin Oncol 7: 275-283, 2016.

14 Ara SA, Mudda JA, Lingappa A and Rao P: Research on curcumin: A meta-analysis of potentially malignant disorders. J Cancer Res 12: 175-181, 2016.

15 Mohandas KM and Desai DC: Epidemiology of digestive tract cancers in India. V. Large and small bowel. Indian J Gastroenterol 18: 118-121, 1999.

16 Chen A, Xu J and Johnson AC: Curcumin inhibits human colon cancer cell growth by suppressing gene expression of epidermal growth factor receptor through reducing the activity of the transcription factor Egr-1. Oncogene 25: 278-287, 2006.

17 Mudduluru G, George-William JN, Muppala S, Asangani IA, Kumarswamy R, Nelson LD and Allgayer H: Curcumin regulates miR-21 expression and inhibits invasion and metastasis in colorectal cancer. Biosci Rep 31: 185-197, 2011.

18 Lim TG, Lee SY, Huang Z, Lim DY, Chen H, Jung SK, Bode AM, Lee KW and Dong Z: Curcumin suppresses proliferation of colon cancer cells by targeting CDK2. Cancer Prev Res 7: 466-474, 2014.

19 Chen CC, Sureshbabul M, Chen HW, Lin YS, Lee JY, Hong QS, Yang YC and Yu SL: Curcumin Suppresses Metastasis via Sp-1, FAK Inhibition, and E-Cadherin Upregulation in Colorectal Cancer. eCAM 2013: 541695, 2013.

20 Rodrigues NR, Rowan A, Smith ME, Kerr IB, Bodmer WF, Gannon JV and Lane DP: p53 mutations in colorectal cancer. Proc Natl Acad Sci USA 87: 7555-7559, 1990.

21 Iida N, Fujita M, Miyazawa K, Kobayashi M and Hattori S: Proteomic identification of p38 MAP kinase substrates using in vitro phosphorylation. Electrophoresis 35: 554-562, 2014.

22 Kosako H, Yamaguchi N, Aranami C, Ushiyama M, Kose S, Imamoto $\mathrm{N}$, Taniguchi $\mathrm{H}$, Nishida $\mathrm{E}$ and Hattori $\mathrm{S}$ : Phosphoproteomics reveals new ERK MAP kinase targets and links ERK to nucleoporin-mediated nuclear transport. Nat Struct Mol Biol 16: 1026-1035, 2009.

23 Ueda K, Kosako H, Fukui Y and Hattori S: Proteomic identification of Bcl2-associated athanogene 2 as a novel MAPK-activated protein kinase 2 substrate. J Biol Chem 279: 41815-41821, 2004.

24 Sato T, Ishii J, Ota Y, Sasaki E, Shibagaki Y and Hattori S: Mammalian target of rapamycin (mTOR) complex 2 regulates filamin A-dependent focal adhesion dynamics and cell migration. Genes Cells 21: 579-593, 2016. 
25 Huang da W, Sherman BT and Lempicki RA: Systematic and integrative analysis of large gene lists using DAVID bioinformatics resources. Nat Protoc 4: 44-57, 2009.

26 Huang da W, Sherman BT and Lempicki RA: Bioinformatics enrichment tools: paths toward the comprehensive functional analysis of large gene lists. Nucleic Acids Res 37: 1-13, 2009.

27 Bode AM and Dong Z: Post-translational modification of p53 in tumorigenesis. Nat Rev Cancer 4: 793-805, 2004.

28 Stein SC, Woods A, Jones NA, Davison MD and Carling D: The regulation of AMP-activated protein kinase by phosphorylation. Biochem J 345 Pt 3: 437-443, 2000.

29 Inoki K, Kim J, and Guan KL: AMPK and mTOR in cellular energy homeostasis and drug targets. Annu Rev Pharmacol Toxicol 52: 381-400, 2012.

30 Wang J, Zhang J, Zhang CJ, Wong YK, Lim TK, Hua ZC, Liu B, Tannenbaum SR, Shen HM and Lin Q: In situ proteomic profiling of curcumin targets in het 116 colon cancer cell line. Sci Rep 6: 22146, 2016.
31 Xie J, Wang X and Proud CG: mTOR inhibitors in cancer therapy. F1000Res, 2016. doi: 10.12688/f1000research.9207. [Epub ahead of print]

32 Pan W, Yang H, Cao C, Song X, Wallin B, Kivlin R, Lu S, Hu G, Di W and Wan Y: AMPK mediates curcumin-induced cell death in CaOV3 ovarian cancer cells. Oncol Rep 20: 1553-1559, 2008.

33 Bossi G, Lapi E, Strano S, Rinaldo C, Blandino G and Sacchi A: Mutant p53 gain of function: reduction of tumor malignancy of human cancer cell lines through abrogation of mutant p53 expression. Oncogene 25: 304-309, 2006.

Received June 16, 2017

Revised July 4, 2017

Accepted July 5, 2017 